\title{
ESCRITA ACADÊMICA: REPERCUSSÕES E RESSONÂNCIAS PROPAGADAS EM UM COLETIVO
}

ACADEMIC WRITING: REPERCUSSIONS AND RESONANCES PROPAGATED IN COLLECTIVITY

\section{ESCRITURA ACADÉMICA: REPERCUSIONES Y RESONANCIAS PROPAGADAS EN UN COLECTIVO}

\section{Vivien Kelling Cardonetti ${ }^{1}$}

Marilda Oliveira de Oliveira²

\section{${ }^{1}$ Doutora em Educação pela Universidade Federal de Santa Maria (UFSM), Santa Maria, RS, Brasil.}

2 Doutora em História, Geografia e História da Arte pela UB. Docente do Programa de PósGraduação em Educação da Universidade Federal de Santa Maria (UFSM), Santa Maria, RS, Brasil.

Resumo: Este artigo busca tecer discussões em relação à produção da escrita acadêmica. Tem como propósito investigar as repercussões e as ressonâncias que foram propagadas no movimento de ler, escrever e partilhar as pesquisas em um grupo de pós-graduação em educação. A intenção é interrogar e problematizar os movimentos e os pensamentos que atravessam uma escrita acadêmica quando produzida no coletivo. Alguns questionamentos estiveram presentes neste percurso: que textos-leituras brotaram deste compartilhamento de leituras? Que textos-leituras respingaram nas escritas acadêmicas dos envolvidos? Que repercussões e ressonâncias foram propagadas na experiência de ler as investigações dos colegas e escrever as próprias pesquisas? Dessa forma, com intuito de atender aos anseios desta investigação, optou-se pela perspectiva narrativa, presentificada no atravessamento de múltiplas vozes e no compartilhamento de experiências dos envolvidos, como forma de pensar o que foi possível aprender neste processo. Alguns conceitos passaram a movimentar o pensamento dessa investigação: repercussão e ressonância (BACHELARD, 1993), leitura e escrita (BARTHES, 2007a, 2007b, 2012; DELEUZE, 2006a, 2006b; DELEUZE; GUATTARI, 1995a, 1995b, 2005; SKLIAR, 2014). As problematizações suscitadas a partir dos autores convidados e das narrativas dos envolvidos agiram como um vetor de ressonâncias, brindando com a oportunidade de pensar algumas possibilidades em relação à escrita acadêmica.

Palavras-chave: Escrita acadêmica; Repercussão, Ressonância.

Abstract: This paper aims to promote discussions on the production of academic writing. Its purpose is to investigate the repercussions and resonances that were propagated in the movement of reading, writing and sharing research in a postgraduate research group in Education. The intention is to question and investigate the movements and thinking that underlie academic writing when produced in the collectivity. Some questions were present in this research: what texts/readings came out of this sharing of readings? What texts/readings overflowed into the participant's academic writings? What repercussions and resonances were propagated through the experience of reading their classmates' investigations and writing their own research? Seeking to achieve the research goals, a narrative approach was adopted, which was materialized through the crossing of multiple 
voices and in the sharing of experiences of those involved, in order to reflect on what could be learned from this process. Some concepts formed the basis of thought underlying this research: repercussion and resonance (BACHELARD, 1993), reading and writing (BARTHES, 2007a, 2007b, 2012; DELEUZE, 2006a, 2006b; DELEUZE and GUATTARI, 1995a, 1995b, 2005; SKLIAR, 2014). The investigations prompted by these authors, and the participants' narratives, acted as a vector of resonances, bringing the opportunity to think about some possibilities in relation to academic writing. Keywords: Academic writing; Repercussion; Resonance.

Resumen: Este artículo busca tejer discusiones con relación a la producción de la escritura académica. Tiene como propuesta investigar los rebotes y las resonancias con propagación en el movimiento de leer, escribir y compartir las investigaciones en un colectivo de posgrado en educación. La intención es interrogar y problematizar los movimientos y pensamientos que cruzan una escritura académica cuando producida en el colectivo. Algunos interrogantes estuvieron presentes en este recorrido: ¿qué textos lecturas surgieron del intercambio de lecturas? ¿Qué textos lecturas salpicaron en las escrituras académicas de los colaboradores? ¿Qué rebotes y resonancias fueron propagadas en la experiencia de leer las investigaciones de los colegas y escribir las propias investigaciones? De esa forma, con intuito de atender a los propósitos de esta investigación, se optó por la perspectiva narrativa, presentificada en el cruce de múltiples voces y en el intercambio de experiencias de los colaboradores, como forma de pensar lo que fue posible aprender en este proceso. Algunos conceptos pasaron a mover el pensamiento de esta investigación: rebote y resonancia (BACHELARD, 1993), lectura y escritura (BARTHES, 2007a, 2007b, 2012; DELEUZE, 2006a, 2006b; DELEUZE y GUATTARI, 1995a, 1995b, 2005; SKLIAR, 2014). Las problematizaciones suscitadas desde los autores y las narrativas nos dieron la oportunidad de pensar algunas posibilidades con relación a la escritura académica.

Palabras clave: Escritura académica; Rebote; Resonancia.

\section{UM BREVE PANORAMA}

Por que se debruçar no estudo da escrita acadêmica? Que repercussões e ressonâncias são propagadas no movimento de ler, escrever e compartilhar as pesquisas em um grupo de pós-graduação? Estas questões têm a intenção de abrir a discussão desse campo de estudo que tem sido tema da pesquisa de pós-doutorado da primeira autora.

A pesquisa, ainda em andamento, tem buscado investigar outras vias de uma escrita acadêmica, explorando como acontece o atravessamento das leituras e das escritas realizadas e problematizadas em um coletivo. Nesse sentido, buscou-se materialidade nas investigações da turma de mestrandos, doutorandos e pós-doutorandos do Programa de Pós-Graduação em Educação (PPGE), da linha de Pesquisa Educação e Artes, da Universidade Federal de Santa Maria (UFSM).

Esse grupo, que está sob a orientação da segunda autora, há alguns anos tem tentado criar outras possibilidades de vida no âmbito da educação menor, tem invencionado outras escritas no seu campo de atuação, tem investido em linhas de fuga e produzido pequenos sulcos e fendas no texto, para que o sopro de ar benfazejo possa envolver e renovar aqueles ao qual fazem uso.

Os componentes do grupo têm se dedicado esses últimos anos ao estudo e à leitura das obras de alguns autores como: Gilles Deleuze, Gilles Deleuze e Félix Guattari, Maurice Blanchot, Roland Barthes, Carlos Skliar, Jorge Larrosa e Sandra Corazza. 
Além de fazer a leitura e a discussão das obras desses autores, os pós-graduandos são convidados, a cada dois meses, durante todo o ano, a fazer a leitura dos projetos de pesquisa dos colegas e, também, a produzir uma escrita em forma de parecer contributivo que é lido e entregue no dia do encontro. Para cada encontro de orientação coletiva, todo o componente apresenta seu projeto e lê cerca de cinco a seis projetos.

Esse cruzamento de leituras contribui para que se pense nas investigações dos outros, como também nas pesquisas pessoais, concorrendo para um profícuo jogo de intercâmbios. Ao ler a pesquisa do colega, é possível olhar para a própria investigação de forma deslocada, contribuindo para que se repensem algumas questões que estão naturalizadas.

É pensando em tudo isso, que a intenção neste texto é interrogar e problematizar os movimentos e os pensamentos que rasgam, cortam e atravessam uma escrita acadêmica quando produzida no coletivo. Intentam-se também pesquisar e explorar esse panorama multifacetado que faz potencializar o compartilhamento de leituras e a eclosão da escrita em um grupo de pós-graduação.

\section{QuAndo a metodologia nos ACOLHE}

Durante a pesquisa, a atenção esteve voltada para as repercussões e as ressonâncias que o compartilhamento das leituras e das escritas puderam reverberar nos envolvidos, procurando pensar sobre o que foi possível aprender neste processo e de que forma o grupo foi se movimentando e se produzindo.

Para tanto, buscou-se tratar as narrativas dos envolvidos neste texto como forma de fomentar o diálogo e a problematização junto às leituras realizadas, junto aos conceitos dos autores convidados e, também, junto ao movimento do pensamento das autoras. Dessa forma, entrelaçaram-se os pensamentos dos participantes, dos autores convidados e das investigadoras.

Nesta direção, optou-se pela abordagem de pesquisa de perspectiva narrativa, com o propósito de atender os anseios da investigação, possibilitando que se estabelecesse "a experiência como pauta de discussão ou como focos de investigação" (OLIVEIRA, 2011, p. 178).

Ao narrar, não se está apenas se detendo em descrever eventos e percepções. Narrar é também criar, pois aquele que narra "tem a oportunidade de revisitar e reorganizar sua experiência de modo que ela adquira (...) sentido e significado ao evento ou situação relatadas" (MARTINS; TOURINHO, 2009, p. 3). O narrador passa a escutar os outros e a si mesmo, fazendo relações que talvez não estivessem tão claras. Essa imersão pode propiciar um momento de contato com situações e eventos construídos durante sua vida e um olhar demorado sobre determinados momentos, possibilitando que outras tessituras possam ser tramadas.

Quando se estudam as narrativas de outros, passa-se a transitar em mundos que se desconhece, pois se entrelaçam pensamentos e impressões diferenciadas. Essa multiplicidade contribui para que novas composições sejam acionadas, possibilitando outras produções de sentido.

A importância das narrativas está naquilo que elas provocam a pensar e nas outras conexões que elas desafiam a realizar. Por isso, é possível dizer que, ao fazer a opção por uma investigação de caráter narrativo, também se estão levando em consideração o cruzamento 
e o compartilhamento, pois tanto os colaboradores como os pesquisadores estão envolvidos neste processo.

Nesse cruzamento de olhares, granjeado por meio das ressonâncias propagadas e das problematizações suscitadas, é que a construção coletiva vai acontecendo durante o processo de investigação. É nesse tensionamento existente entre a produção de saber coletivo e a de saber particular que narrativas são partilhadas, sobrepostas e contaminadas, possibilitando que outras escritas possam ser engendradas.

\section{A PROBLEMÁTICA QUE ENVOLVE A PESQUISA}

No livro Rumor da Língua, Roland Barthes (2012, p. 26) lança um questionamento: “Nunca Ihe aconteceu, ao ler um livro, interromper com frequência a leitura, não por desinteresse, mas, ao contrário, por afluxo de ideias, excitações, (...)? Numa palavra, nunca lhe aconteceu ler levantando a cabeça?".

Sim... Sim.... Inúmeras vezes se produzem sulcos no texto, embriagados e arrebatados pela potência das palavras e pela energia com que elas se lançam ao horizonte distante. Por vezes, a própria cadência do que é lido e do que não é arremessa ao deleite do fortuito, daquilo que é contingente. Retorna-se desse devaneio com uma série de outras palavras que teimam também em fazer parte do texto. Ao retornar à leitura, essa passa a ter outro sabor e sentido.

Um "texto-leitura" é escrito na cabeça quando se a ergue (BARTHES, 2012, p. 27). Imprimese na leitura de um texto um novo texto. Ele é vivo, pulsante e intenso, ele é a experiência. Isto se amplia quando a leitura é feita no coletivo, pois se passa a compartilhar impressões e digressões, advindo a produção de outras fissuras no texto lido.

Trazendo essas colocações para a investigação, poder-se-ia pensarque os atravessamentos de leituras e escritas realizadas junto ao grupo de Pós-Graduação em Educação, foco de pesquisa em questão, são potentes para investigar a produção de fendas no texto lido e a criação de textos-leituras quando realizadas no panorama plural.

A repercussão deste cruzamento de leituras e escritas foi um convite para que os envolvidos olhassem para as suas próprias investigações e as ressonâncias propagadas passaram a ser dissipadas e exploradas pelo grupo nas inúmeras esferas da vida. Como assevera Oliveira (2015, p. 444), "nossa escrita não é neutra, é contaminada pelas leituras que realizamos, pelos coletivos dos quais participamos".

É nesse sentido que os problemas que envolvem essa pesquisa são: que textos-leituras brotaram deste compartilhamento de leituras? Que textos-leituras respingaram nas escritas acadêmicas dos envolvidos? Que repercussões e ressonâncias foram propagadas na experiência de ler as investigações dos colegas e escrever as próprias pesquisas?

\section{UM OLHAR ATENTO PARA OS CONCEITOS}

Alguns conceitos foram convidados a se presentificarem nesta pesquisa, passando a transitar e transbordar nos encontros, atravessando e movimentando o pensamento desta investigação. A teoria tem sentido quando ela é operativa, quando ela contribui e faz movimentar outras questões. Deleuze e Guattari afirmam que "os conceitos são centros de 
vibrações, cada um em si mesmo e uns em relação aos outros. É por isso que tudo ressoa, em lugar de se seguir ou de se corresponder" (2005, p. 35).

Em seu livro 'A poética do Espaço', Gaston Bachelard (1993, p. 7) pesquisa os espaços na poesia como imagens poéticas que repercutem e ressoam. Entretanto, nesta escrita, interessa adentrar nas relações que ele tece entre repercussão e ressonância na experiência de leitura. Para o autor

... as ressonâncias dispersam-se nos diferentes planos da nossa vida no mundo; a repercussão convida-nos a um aprofundamento da nossa própria existência. Na ressonância ouvimos o poema [texto]; na repercussão o falamos, ele é nosso. (BACHELARD, 1993, p. 7).

Na repercussão, o texto que se lê reverbera em nós, a ponto de se ser capturado e atingido, passando a fazer parte das nossas entranhas. Nesta atmosfera acontecimental, em que se experiencia a leitura, uma imagem é oferecida, ela passa a ser nossa, ela adere e faz liga. Bachelard (1993, p. 7-8) expõe que "a imagem torna-se um ser novo da nossa linguagem, exprime-nos tornando-nos aquilo que ela expressa - noutras palavras, ela é ao mesmo tempo um devir de expressão e um devir de nosso ser". Poder-se-ia afirmar, nesse sentido, que esta imagem estará permeada de uma 'sonoridade do ser'.

O mesmo autor acentua que "é depois da repercussão que podemos experimentar as ressonâncias" (1993, p. 7). Se é apanhado por imagens que repercutem no próprio ser, e é nessa multiplicidade que algumas imagens também acabam escapando e outras são criadas, passando a ampliar o leque de ação. O movimento das imagens que esquivam e evadem passam a sulcar outras fendas, permitindo que as ressonâncias se alastrem.

As ressonâncias têm a propriedade de se dissiparem, de se dispersarem, ampliando o campo de atuação. Essa propagação vibratória produz ecos que possibilitam diferentes relações com outros elementos, fazendo brotar distintas composições, para além do esperado.

Gilles Deleuze e Félix Guattari operaram com o conceito de ressonância em suas obras, principalmente quando estabelecem relações e dialogam com muitos dos conceitos trabalhados, pois cada conceito acaba ressoando em outro. Percebe-se também que eles têm a propriedade de movimentar outras vibrações no mesmo conceito, mesmo que contraditórias, pois, a partir da trama de outros elementos ao conceito anteriormente desenvolvido, vão-se compondo outros arranjos e outras ressonâncias são alastradas. Eles vão oferecendo, a cada página, novas indagações, diferentes tessituras e material para se pensar a própria vida. Como observa Deleuze,

... a ressonância não se baseia em pedaços que lhe seriam fornecidos pelos objetos parciais, nem totaliza pedaços que viriam de outro lugar. Ela extrai seus próprios pedaços e os faz ressoar segundo sua finalidade específica, mas não os totaliza, visto que se trata sempre de um 'corpo a corpo', de uma 'luta' ou de um 'combate'. O que é produzido pelo processo de ressonância, na máquina de fazer ressoar, é a essência singular, o ponto de vista superior aos dois movimentos que ressoam, em ruptura com a cadeia associativa que vai de um a outro. (2006a, p. 144, grifo do autor).

Quando se trabalha coletivamente e se compartem impressões e experiências, é possível produzir vibrações de maior amplitude. As repercussões de cada um se alastram nos outros e se ampliam, misturam-se com outros elementos e acabam produzindo inusitadas ressonâncias, contribuindo para que outros sentidos aos nossos encontros aconteçam. O que está em jogo, nesta paisagem plural, é a potência da conjugação ressonância-repercussão. 
Além da repercussão e da ressonância, mais dois conceitos merecem um olhar atento: leitura e escrita. Carlos Skliar, em seu livro 'Desobedecer a linguagem', coloca que "quando se escreve e se lê, nesse precioso instante em que as folhas permanecem tensas e trêmulas, é que existe escrita e leitura" (2014, p. 122). Há escrita e leitura quando se desapega das certezas e do que é previsto, buscando experienciar intensamente as diferentes possibilidades que vão surgindo no decorrer da escrita e permitindo "deixar de ser, de dar-se de bruços com a impossibilidade de fazê-lo, de estar do lado do desassossego" (SKLIAR, 2014, p. 65).

O tensionamento com aquilo que é desconhecido e adverso permite que o pensamento seja coagido, forçado e violentado a pensar outras coisas, interrompendo a apatia e a paralisia que aprisionam.

Deleuze e Guattari explicitam que "escrever nada tem a ver com significar, mas com agrimensar, cartografar, mesmo que sejam regiões ainda por vir" (1995a, p. 13). A intenção não é oferecer significados e verdades a serem descobertas ou decifradas, mas sim lançar uma escrita com algumas demarcações que possam vibrar, palpitar, latejar e persistir, disparando novas forças e problemas. É este perdurar que convida a provocar outro pensar.

“Escrever implica calar-se, (...), fazer-se 'silencioso como um morto', tornar-se o homem a quem se recusa a última réplica, escrever é oferecer, desde o primeiro momento, essa última réplica ao outro" (BARTHES, 2007b, p. 14). Esse fragmento de Barthes instiga a pensar que uma escrita necessita estar permeada de vacúolos de silêncio para que o leitor tenha algo a dizer/ pensar e disponha da chance de duvidar, contestar, refutar e acrescentar. É no calar tensionado do autor que o leitor poderá criar inusitadas e singulares relações com o texto, produzindo outras construções de sentido com ele.

"Uma tela pode ser inteiramente preenchida, a ponto de que mesmo o ar não passe mais por ela; mas algo só é uma obra de arte se, (...), guarda vazios suficientes para permitir que neles saltem cavalos" (DELEUZE; GUATTARI, 2005, p. 215). Como na tela, uma escrita, quando totalmente preenchida, ela não permite intervenções, não convida a interagir e não possibilita o diálogo. Tudo que está explicado a ponto de se tornar uma verdade absoluta pode vedar as possibilidades de invenção, pois não oportuniza espaço para pensar de outra maneira.

As lacunas e os vazios deixados no texto podem propiciar que os atravessamentos aconteçam e que o imprevisto possa fazer-se presente, permitindo a interferência. A escrita, quando permeada de espaços abertos, pode ser experienciada de uma forma renovada, pois o leitor é convidado a partícipe do que está lendo.

Sente-se contrariado quando nada se tem a fazer, quando tudo está preenchido, determinado, quando se sente à parte da leitura. Existem "tantos bordões que nada está aberto. Nenhuma possibilidade de experiência. Tudo aparece de tal modo que está despojado de mistério, despojado de realidade, despojado de vida" (LARROSA, 2010, p. 49).

As brechas e os vazios ressoam, eles emanam vibrações que desafiam à invenção, e não à reprodução. Esses espaços lacunares podem desempenhar um silêncio tensionador, invitando a intervir e a produzir outras possibilidades no texto lido.

Barthes declara que "escrever é deixar que os outros fechem eles próprios nossa própria palavra, e a escritura é apenas uma proposta cuja resposta nunca se conhece" (2007b, p. 
184-185). Essa colocação impulsiona a pensar que escrever é uma ação que vai além da obra e, talvez, os hiatos deixados por quem escreve seja um convite ao leitor para criar outras possibilidades. A escrita, nesta perspectiva, passa a ser desdobrada juntamente com o leitor e não decodificada por ele. Ela vai fazendo sentido no decorrer da leitura, mas com a intenção de nunca se fixar, e sim volatizar-se.

Essa vaporização contribui para que outros sentidos sejam produzidos, que outros vincos possam ser invencionados, levando a língua a delirar, a variar. "O texto é o próprio aflorar da língua" (BARTHES, 2007a, p. 16), e é essa língua que pode ser sulcada, rasgada e atravessada por uma língua estrangeira. "Ser um estrangeiro, mas em sua própria língua, e não simplesmente como alguém que fala uma outra língua, diferente da sua. Ser bilíngue, multilíngue, mas em uma só e mesma língua" (DELEUZE; GUATTARI, 1995b, p. 42-43). Nas pesquisas em educação, o maior desafio está em levar a própria língua a gaguejar. Aventurarse na proliferação de sentidos, nos desvios inesperados, nas pregas e nos vincos fecundos.

Skliar (2014, p. 129, grifo do autor) coloca que ao se transitar pela academia, somos "reprimidos fortemente ao escrever nossas próprias experiências - em lugar de pesquisar ou estudar a realidade de outros - com nossas próprias palavras - em lugar de adequar-nos às palavras que estão em voga". Escrever as experiências com as próprias palavras é deixar que uma língua viva e pulsante seja atravessada, é permitir que uma língua estrangeira passe a viver na própria língua.

As escritas que fazem degustar outros sabores e prazeres são aquelas que fazem a língua gaguejar, trapacear, titubear. Deleuze (2006b, p.126) explana que "a gagueira criadora é o que faz a língua crescer pelo meio, como a grama, o que faz da língua um rizoma em vez de uma árvore, o que coloca a língua em perpétuo desequilíbrio".

O rizoma é um arranjo aberto, sempre em vias de escapar, extravasar e romper. É uma multiplicidade que não permite ser dirigida e conformada por uma estrutura. Por isso é que se abre a possibilidade de brotar pelo meio, de iniciar 'entre' as coisas, em deslocamento.

\section{COMPARTILHAMENTOS QUE INSTIGAM A PROBLEMATIZAR A LEITURA E A ESCRITA ACADÊMICA}

Que textos-leituras brotaram do compartilhamento de leituras? Que textos-leituras respingaram nas escritas acadêmicas dos envolvidos? Que repercussões e ressonâncias foram propagadas na experiência de ler as investigações dos colegas e escrever as próprias pesquisas?

Com o intuito de tentar pensar algumas possibilidades para essas questões lançadas na pesquisa, se irá valer de algumas narrativas pontuadas no grupo de pós-graduação, objeto de estudo desta investigação.

"São os extravios que tem nos movimentado enquanto grupo. Tem maior relevância aquilo que perdemos e deixamos lá do que aquilo que levamos embora quando o encontro acaba" (narrativa da orientadora do grupo de pesquisa).

Deixar-se extraviar... Perder-se no percurso que foi programado... Aventurar-se em caminhos ainda não trilhados... Esses são movimentos que, por se temer o desconhecido, recusa-se. Priva- 
se de experienciar e pensar outras coisas quando se está imune a um cenário não costumeiro.

O contexto conhecido passa a ser o único campo de atuação, e por isso se passa, às vezes, a não perceber os caminhos que rodeiam. Por não se estar familiarizado com alguns signos, por não se permitir uma experiência com eles, ou melhor, por não se explorar o que o encontro com esses signos (DELEUZE, 2006a) pode inaugurar, passa-se a não experienciá-los.

As escolhas e os trajetos não precisam ser os mesmos, tampouco serem trilhados da mesma forma. Existe uma infinidade de vias não visualizadas e que ainda não foram inventadas. O desafio talvez se encontre em viver intensamente esse descaminho, experienciando situações imprevisíveis, bifurcantes e desviantes, com o intuito de reinventar e produzir a todo instante.

Outra possibilidade para o extravio também é oferecida na parte final desta narrativa: Tem maior relevância aquilo que perdemos e deixamos lá do que aquilo que levamos embora quando o encontro acaba. Esse fragmento incita a pensar como é desafiador abandonar certas coisas que estão grudadas, aderidas e fixadas em nós. Essa ação, por vezes dolorosa, provoca desapegar da estagnação, impelindo a desconjuntar, fraturar, deformar e intervir em nós mesmos.

Fernando Pessoa convida a se deter na questão do desapego, brindando com esse verso: Há um tempo em que é preciso abandonar as roupas usadas, que já tem a forma do nosso corpo, e esquecer os nossos caminhos, que nos levam sempre aos mesmos lugares. Em seguida ele chama a atenção: É o tempo da travessia: e, se não ousarmos fazê-la, teremos ficado, para sempre, à margem de nós mesmos.

Entretanto, vale pontuar que essa atitude que o poeta brinda demanda desprendimento e deslocamento. Por isso é possível questionar: como permitir o extravio daquilo que prende ao mesmo, ao que está naturalizado e que dá segurança? Como 'desaprender' o que já se sabe, de se desapegar de verdades fixas e limitadoras e se abrir ao que não se sabe, a algo que não está previsto?

"Experimentar um tecer de linhas, que procurou escapar de um comunicar: o processo de escrita é a própria experimentação, permeada por um fazer corpo dessas linhas de escrita, linhas da vida. Um fiandar que persiste em meio à docência, como resistir nos espaços e discursos que nos adoecem. Uma cura, um fiandar infinito" (narrativa da componente A do grupo de pesquisa).

"A leitura que de-forma, que desforma, que des-in-forma, que arranca o rosto, que faz, quem sabe, fazer esse leitor entrar num devir-mosca, que passeia pelo amontoado de teias que é o texto. Des-instaurar esse lugar do leitor porque o lugar de autor também foi desinstaurado" (narrativa da componente A do grupo de pesquisa).

Estes dois fragmentos provocam a pensar algumas questões: como fazer brotar entre as palavras da escrita acadêmica outras sonoridades? Como povoar a leitura e a escrita de possibilidades, distanciando-se da informação, do relato, do senso comum e daquilo que faz cantar sempre em uníssono? Que forças podem levar a ser os regentes da própria escrita e leitura? Como potencializar a escrita de forma que ela se torne experimentação e o leitor consiga entoar outros timbres e inflexões com ela e para além dela? 
Mais um questionamento rasga essa escrita, insistindo fazer parte dessas questões já enunciadas: qual a intenção de ler e escrever de forma que as palavras repercutam e ressoem? Deleuze e Guattari oferecem uma possível resposta, quando eles colocam que "cantar ou compor, pintar, escrever não têm talvez outro objetivo: desencadear (...) devires" (2008, p. 63).

Os devires disparados na leitura e na escrita fazem pensar nas experiências limiares e fronteiriças que atuam no 'entre', nas adjacências e nas fendas de um texto. Incitam também a pensar neste incessante processo contínuo e inventivo que está a se movimentar e se alterar 'em meio', rompendo com os pontos prefixados, com as segmentações e com as estratificações.

O devir é uma experiência revolucionária, pois se manifesta na disposição em abdicar de uma circunstância fixada ou infligida, demandando uma energia que impressiona, uma potência inventiva, uma paixão pelo inexplorado.

É nesse sentido que os devires remetem a uma força que invade e que brota de maneira intensa, é um arrombamento que traz a novidade e não a comprovação, que traz a invenção e não a representação, passando a produzir vestígios de uma vivificação constante. Está 'entre', 'em meio', formando blocos que se movimentam e adotam suas próprias linhas, expandindo os heterogêneos por relações de aliança, por contágio.

"Já não é a sintaxe formal ou superficial que regula os equilíbrios da língua, porém uma sintaxe em devir, uma criação de sintaxe que faz nascer a língua estrangeira na língua, uma gramática do desequilíbrio" (DELEUZE, 2006b, p.127). É essa potência inventora que impulsiona a escrita a delirar, a gaguejar e a balbuciar, reinventando-se a todo momento.

A experiência de escrever possibilita conhecer insólitos cenários e pessoas, colocando a atuar em outros papéis e situações. Esse movimento faculta que se venha a vivenciar distintas possibilidades, propiciando ser de uma maneira diversa do que se vinha sendo, reconhecendo o inacabamento. A escrita, nesse sentido, é performativa, pois opera sobre o vivido, permitindo experimentar e experienciar outros possíveis.

"Que fluxos de forças atravessam o 'entre' que se aloja em meio a leituras e escritas? Pode uma escrita científica ser composta com blocos de sensações? Com afetos e visualidades que vem produzir vizinhança com linhas de escrita, tecendo composições que não se pretendem fechadas, conclusas, mas que deixam vazios a serem experienciados por quem se aventurar em suas fissuras?" (narrativa da componente $B$ do grupo de pesquisa).

"Que leituras e escritas nos convidam a nos tornarmos outros? Que leituras e escritas nos repetem e reforçam? Que leituras e escritas nos fazem desconfiar de nós e de nossas certezas? Que leituras e escritas as reforçam?" (narrativa da componente B do grupo de pesquisa).

Com intuito de problematizar estas questões lançadas por mais uma componente do grupo de pesquisa, recorro à colocação de Carlos Skliar. Esse autor expõe que é necessário se rever os questionamentos que se faz em relação à escrita, pois a questão a ser pronunciada "não é: o que é a escrita? Mas sim: como chegamos a ela?" (2014, p. 134). O que se fazemos com ela e o que ela faz conosco?

Essa forma diversa de questionar abre a possibilidade de se vislumbrar outra maneira de 
se conectar com a escrita, produzindo outras construções de sentidos. Poderia estender essa questão também para a leitura e questionar: como se chega à leitura? Desejando explorar essas questões que latejam, repercutem e ressoam, algumas linhas passam a ser escritas.

Chega-se à leitura e à escrita trilhando caminhos que outros recusaram, rebelando-se com o preestabelecido, aproximando-se da impossibilidade, estando atento para as inusitadas direções, fazendo as palavras vibrarem para além das linhas, semeando palavras desobedientes e movediças, olhando para o que já foi visto, todavia de outra maneira.

Chega-se à escrita e à leitura quando se expande o instante, quando se repara para o ínfimo e para o que ainda não foi nomeado, quando se capturam palavras rejeitadas e se passa a dispô-las de forma diferente, quando se faz a vida transbordar e vazar entre as palavras, quando se dilui e se suplanta o eu, quando se abre aos afetos, aos fluxos de intensidades e aos devires, quando se povoam as linhas com convites à pausa, ao suspiro, ao gemido, ao sorriso e à aproximação de outras linhas.

Nesse sentido, é possível afirmar que leitura-escrita está imbricada a todo momento, pois é

... um processo que se produz em concomitância, diferente de uma estrutura que se define por um conjunto de pontos de posições prévias. Ler-escrever de forma que possamos produzir uma variação no próprio texto. Construir um texto desmontável, conectável, nômade, com linhas de fuga, destituído

do fundamento de base. Iniciar pelo meio, onde as coisas adquirem velocidade, percorrer as margens, despersonalizar o próprio corpo para ter condições de nomear a própria pesquisa. (OLIVEIRA, 2015, p. 452).

Esse fragmento convoca a pensar que ler e escrever são "potências vivas e inseparáveis. Lê-se porque se escreve, escreve-se porque se lê. Escreve-se enquanto se lê e lê-se aquilo que se escreve" (MOSSI, 2016, p. 71). E é neste movimento imanente de forças que se expande o instante e se passa a soerguê-lo. Um novo tempo é produzido, outros modos de viver são experienciados, e é neste momento que se inventa uma nova língua na nossa língua e se passa a ler e escrever, a escrever e ler...

\section{O QUE SE APRENDE COM ESSA EXPERIÊNCIA? AlguMAS POSSIBILIDADES}

Problematizar as narrativas que repercutiram e ressoaram das leituras dos autores selecionados e das pesquisas partilhadas entre os participantes do grupo de orientação propiciou material para este texto. Neste cenário intenso se exploraram o atravessamento de múltiplas vozes e o compartilhamento de experiências, como também se teve a possibilidade de afetar e ser tocado, de aprender e também ensinar.

Dessa forma, deixar-se envolver por outras forças em exercício, o que impulsionou a fazer diferentes relações com os nossos estudos. Esse deslocamento fez incorporar uma dinâmica de reavaliação, potencializando o enriquecimento de nossa escrita acadêmica.

Ao evocar e atualizar cada cena deste passado próximo, é possível perceber o quanto o compartilhamento entre os envolvidos foi significativo para nossas investigações. Ao interagir com as singularidades e com a generosidade da leitura dos colegas, com a doação no sentido de deixar ser visto sem máscaras e com as experiências que não eram nossas, mas passaram a ser, 
foi possível conceber e dar corpo também às nossas pesquisas. A partir da potência característica e singular desta coletividade é que as dissertações e as teses do grupo foram escritas.

Como já foi anunciado anteriormente, três questões envolveram e movimentaram a problemática dessa pesquisa. Ao lançar esses questionamentos, a intenção não foi oferecer verdades a serem reproduzidas em relação à escrita acadêmica, mas sim lançar algumas questões e considerações que possam vibrar, palpitar, latejar e persistir, disparando novas forças e, quiçá, outros problemas.

Em relação à primeira questão anunciada - Que textos-leituras brotaram do compartilhamento de leituras? -, foi possível perceber que as escritas produzidas pelo grupo de orientação procuraram "sair do uníssono, fabular, escrever por fragmentos, buscar granulações no texto. Inventar um uso menor para pensar a pesquisa de modo a fazer defeitos nas frases, como diria Manoel de Barros. Singularizar" (OLIVEIRA, 2015, p. 450). Afastadas de um eixo de apoio e de uma linearidade, as escritas criadas por esse coletivo buscaram apostar no inabitual e no imprevisível, trazer para as linhas do texto elementos até então renegados, compor arranjos inconcebíveis e produzir outras construções de sentidos.

O grupo procurou se distanciar de uma escrita autoritária e previsível, abrindo-se às oscilações e às incertezas que fazem parte de uma escrita que está conectada com a vida. Ao levar em consideração os movimentos paradoxais da vida, abriu-se a oportunidade de escrever sem prescrições e sem falsas expectativas para o que está por vir. O desafio foi pensar em uma escrita acadêmica provisória e mutável, sempre em vias de ser, em devir.

As escritas produzidas nessa grupalidade não se detiveram em comunicar sobre algo que já se sabia, mas se dedicaram a explorar e a pensar sobre o que não se sabia, passando a escrever no processo, na experiência. Conforme Julio Groppa (2011, p. 644), "escrever consistiria assim, numa experiência de transformação do que se pensa e, acima de tudo, do que se é, uma experiência ruminação do próprio pensamento, avessa, ademais, a qualquer apelo comunicativo ou normativo".

O segundo questionamento que acompanhou a problemática da investigação foi: Que textos-leituras respingaram nas escritas acadêmicas dos envolvidos? Neste panorama plural e inquieto, em que as experiências de leitura e de escrita foram partilhadas no grupo, passouse a debruçar no tangenciar de composições próprias e alheias, explorando aquilo que se produziu nessa multiplicidade.

A multiplicidade não seria justamente isso? Uma tessitura de dimensões que se deslocam, que se prolongam e se relacionam umas com as outras com intuito de gerar força? Cada uma incorporando todas as outras em outra condição? Sim... A autoria passou a ser questionada, pois a escrita acadêmica produzida neste coletivo foi contagiada e contaminada por muitas mãos.

As fissuras no texto que povoaram as dissertações e as teses do grupo estavam intimamente ligadas aos disparos realizados nas leituras e nos encontros de estudos, na potência dos pareceres dos colegas e da orientadora e, acima de tudo, na energia com que essas fendas passaram a se projetar ao horizonte longínquo. Machado e Almeida (2016, p. 81) corroboram esta questão, afirmando que "o escritor é múltiplo, composição de vozes, 
vidas e ações coletivas. Ao narrar, rouba frases alheias, cochichos escutados ao pé do ouvido, conversas e leituras. Narrador-ladrão, narrador-leitor, narrador-viajante, narrador-multidão".

Com intuito de encerrar provisoriamente essa escrita, convida-se a terceira e última questão que fez parte da problemática de pesquisa: Que repercussões e ressonâncias foram propagadas na experiência de ler as investigações dos colegas e escrever as próprias pesquisas? Essa indagação foi propulsora das inúmeras construções de sentidos produzidas no decorrer deste artigo, convidando a olhar com atenção para as escritas e de que forma elas têm respingado em nossa vida. Por isso, neste instante final, gostar-se-ia de trazer a potente aliança entre escrita e vida.

Ao usufruir dessa intensa zona de vizinhança, passa-se a conjecturar que todo e qualquer texto que se escreve é gotejado por inúmeras vidas, passando a respingar também na nossa própria vida. Isso permite dizer que o que se escreve acaba nos escrevendo; o que se produz também passa a nos produzir. "Eis o ponto exato de culminância entre escrita e vida, em que a primeira se oferece como modo e ocasião para a vertiginosa multiplicação de formas da segunda" (GROPPA, 2011, p. 647).

Poder-se-ia afirmar que a escrita acadêmica, nessa perspectiva, passa a ser uma celebração à vida e uma invenção de vidas. Pois ao se escrever nossas pesquisas e ao se ser afetado por uma multiplicidade de vidas, se é convidado a reinventar a nossa, fazendo-a vibrar até o momento de não se assemelhar mais com ela, todavia sem que se conseguir afirmar que não é.

\section{RefERÊNCIAS}

BACHELARD, G. A poética do espaço [tradução de Antonio de Pádua Danesi]. São Paulo: Martins Fontes, 1993. BARTHES, R. Aula. [tradução de Leyla Perrone-Moisés]. 15. ed. São Paulo: Cultrix, 2007a.

. Crítica e verdade. [tradução de Leyla Perrone-Moisés]. 3. ed. $2^{a}$ reimp. São Paulo: Perspectiva, 2007b.

. O rumor da língua. [tradução de Mario Laranjeira]. 3. ed. São Paulo: Martins Fontes, 2012.

DELEUZE, G. Proust e os Signos [tradução de Antônio Piquet e Roberto Machado]. 2. ed. Rio de Janeiro: Forense Universitária, 2006a.

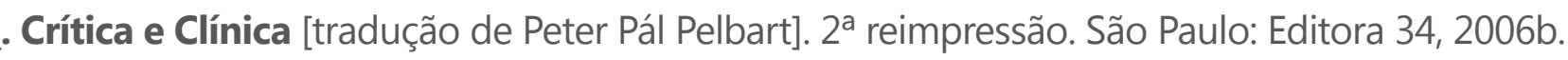

DELEUZE, G.; GUATTARI, F. Mil platôs: capitalismo e esquizofrenia, vol. 1 [tradução de Aurélio Guerra e Célia Pinto Costa]. Rio de Janeiro: Ed. 34, 1995a.

- Mil platôs: capitalismo e esquizofrenia, vol. 2 [tradução de Ana Lúcia de Oliveira e Lúcia Cláudia Leão]. Rio de Janeiro: Ed. 34, 1995b.

. O que é a Filosofia? [tradução de Bento prado Jr. e Alberto Alonso Munhoz]. 2.ed. $4^{\mathrm{a}}$ reimp. Rio de Janeiro: Ed. 34, 2005.

. Mil platôs: capitalismo e esquizofrenia, vol. 4 [tradução de Suely Rolnik]. $4^{a}$ reimp. São Paulo: Ed. 34, 2008.

GROPPA, J. A escrita como modo de vida: conexões e desdobramentos educacionais. Educação e 
Pesquisa, São Paulo, v.37, n.3, p. 641-656, set./dez. 2011.

LARROSA, J. Pedagogia Profana: danças, piruetas mascaradas [tradução de Alfredo Veiga-Neto]. 5. ed. Belo Horizonte: Autêntica, 2010.

MACHADO, L. D.; ALMEIDA, L. P. de. Notas sobre escrever [n] uma vida. RIBETTO, A.; CALLAI, C. (Org.). Uma escrita acadêmica outra: ensaios, experiências e invenções. 1. ed. Rio de Janeiro: Lamparina, 2016. p. 75-85.

MARTINS, R.; TOURINHO, I. Pesquisa Narrativa: Concepções, Práticas e Indagações. II CEAC, UFSM, 2009.

MOSSI, C. P. Escritas, leituras, visualidades: povoamentos para pensar a aula (ou a docência) como zona de pesquisa. Revista Digital do LAV, v. 9, p. 061, 2016.

OLIVEIRA, M. O. de. Por uma Abordagem Narrativa e Autobiográfica: os diários de aula como foco de investigação. In: MARTINS, R.; TOURINHO; I. (Orgs.). Educação da cultura visual: conceitos e contextos. Santa Maria: Ed. Da UFSM, 2011. p.175-190.

Como produzir clarões nas pesquisas em educação? Revista de Educação Pública, v. 24, n. 56, mai/ago, p.443-454, 2015.

SKLAR, C. Desobedecer a linguagem: educar [tradução de Giane Lessa]. Belo Horizonte: Autêntica Editora, 2014.

Artigo recebido em: 18/09/2017 Aprovado em: 12/03/2018

Contato para correspondência: Vivien Kelling Cardonetti. E-mail: vicardonetti@gmail.com 